\title{
Contribution of circular dance on quality of life on oncology patients bearing intestinal ostomy.
}

\author{
Cristilene Akiko Kimura ${ }^{1}$, Dirce Bellezi Guilhem ${ }^{2}$, Ivone Kamada ${ }^{3}$, Renata Costa Fortes ${ }^{4}$, Breno Silva de Abreu \\ ${ }^{1}$ Institutional Supervisor, Sena Aires Science and Education College, Facesa, Brazil. \\ ${ }^{2}$ Professor (Ph.D.), Nursing Post- Graduate Program at the University of Brasilia (UnB) - Brasília (DF), Brazil. \\ ${ }^{3}$ Assistant Professor (Ph.D.), Health Sciences School, Brazil. \\ ${ }^{4}$ Professor, Science and Education College, Sena Aires (Facesa), Brazil. \\ ${ }^{5}$ Doctoral Student, Health Science for the University of (UnB), Brasília, Brazil.
}

Keywords: Quality of life, Ostomy, Therapy through dance, Colorectal cancer, Health policy.

Accepted October 31, 2016

\section{Brief Commentary}

Modern surgery technologies are always being included in ostomy surgery procedures mostly due to the fact that such measure is usually performed in order to attempt to improve patient's survival chances, mostly focused on granting an improved quality of life during the illness, however, only implementing better techniques on surgery does not affect directly the quality of life. The use of complementary measures regarding nursing care as well as dealing with several implications of ostomy surgery on the patient's well-being is an upcoming challenge. On that matter, we assessed the ability of circular dances as a tool to improve the QoL of ostomized patients, as a public health policy program in Brazil, being able to evaluate the importance of nursing care and nursing education in the quality of life scores of patients subjected to such practices.

World Health Organization (WHO) defines quality of life (QoL) as "one's perception of its position in life, contextualized in terms of cultural and value systems in which one lives as well as regarding one's relation towards goals, expectations, standards and preoccupations" [1].

Along that point of view, the matters is greatly subjective which implies personal satisfaction regarding several aspects but especially those considered essential to one's life. The maintenance of the physical integrity is quite important for an individual's well-being and its social surroundings. The rupture of such integrity, as observed on ostomized individual due to colorectal cancer (CCR), might impact strongly on a person's physical, psychological, social and spiritual characteristics [2-5].

The confection of intestinal ostomy can be described as a surgical procedure aiming a temporary or permanent deviation on the colonic effluent, due to several scenarios, such as, intestinal chronic inflammation diseases, traumas and colorectal neoplasy $[3,4,6-8]$. The intestinal ostomized patient fits a profile where colorectal neoplasy is the major reason for the ostomy confection $[3,5,6,9,10]$. The exteriorized portion of the intestines might include the colon or the ileum, respectively named colostomy and ileostomy $[4,11]$.

Based on information supplied by WHO World Cancer Report 2014, from the International Agency for Research on Cancer, its unquestionable that cancer has become a public health issue, especially on developing countries, on which the expectations for the next couple decades is that cancer prevalence shall increase to $80 \%$ of 20 Million new cases for 2025 [12].

CCR is the second most prevalent cancer in the world, having the third higher incidence on man and second higher on women, alas, becoming a major worldwide public health concern. CCR is considered one of the most important neoplasy on World Adult Population, presenting growing incidence and mortality in most of countries $[7,11,13]$.

The oncological patient bearing a intestinal ostomy faces several losses which can be real or symbolic. The evacuation of feces and gas, the constant odor leaking anxiety, physical discomfort and loss of minimal conditions for life in society might lead to psychological and social isolation, becoming more likely to induce additional negative feelings that affects interpersonal relations $[3,5-$ $7,14]$.

Besides that, the ostomy device is a day to day reminder that a body part was lost, requiring the patient to establish new habits obtained through learning, specially focused on self-caring. Furthermore, the intestinal ostomy, specially the CCR derived type, changes the social function of the ostomized person regarding family and society as a whole $[2,4,15]$.

After the surgical procedure, many oncologic patients 
become highly dependent of family care, at least temporarily, but also expose the social imposed disabilities, mostly regarding the sense of independence, efficiency and productivity $[6,15,16]$.

Moreover, an oncologic patient bearing an intestinal ostomy suffers from diminished self-body image and self-esteem concepts, generating a self-targeting sense of rejection. The meaning of alterations of the physical body and suffering, regarding the new lifestyle, have major effects on physical and psychological aspects, as well as influence social relations, one's relation towards the environment, taking a great toll on one's QoL $[3,5,17,18]$.

Having that point of view in mind, the oncology patient bearing an intestinal ostomy demands for long time specialized care in order to keep some level of autonomy, which might help attenuate the impact onto one's QoL, including the patient himself, its family and care givers $[6,15,16]$. One's need for specialized care shall allow a rehabilitation, in a way that is possible to learn to live as an ostomized person and CCR presence, avoiding complications, adopting healthy and adequate diets, have plenty of access to all ostomy related products, always available emotional support and multiprofessional care $[4,8]$.

Along those lines, we believe that complementing activities added to the traditional well established protocol for Ostomized Person Caring, might generate serious contribution for psychological adjustment and social insertion of the intestinal ostomized person. One of those complementing activities included on the Brazilian Unified Health System is Dance, which aims to work with one's organism, in a harmonious way, respecting its emotions and physiological condition. Such practices contribute also to the improvement of motor skills and self-knowledge, gathering benefits such as: Stressful situations prevention, brain oxygen saturation, improved gland function, muscle strengthening and articulation protection, cognitive function improvement, concentration and attention span, improves cooperation, collaboration and social interaction, stimulate creativity, elevates self-image and self-esteem as well as favors the cultural rescue [19-22].

It is possible to detect that, historically; dance is inherent to human nature, existing prior to verbal communication, being able to manifest its feeling through body movements. Thus, Dancing is strongly correlated to living and selfexpression, at the most intensity, of the men/nature relationship, but also towards society, its future and its deities [19,23,24].

The Sacred or Circular Dances seems to able to induce several benefits for the dancer, improving general physical and mental dispositions, flexibility, posture, muscular strength and resistance, conscience, relieving tensions and aches, providing well-being for the individual $[19,21,25,26]$. The dance acts also on mental and emotional spheres, allowing the individual to work on attention span, memory, cognition, language, expression, socializing and minimizing feelings of isolation and solitude [22,24].

Besides that, during the Sacred Dance or Circular Dance, the ambience provided by the activities generates an equilibrium between the individual and the group, strengthening of bonding by the realization that as ostomized person is not alone on its suffering, finding safe harbor on the equality feeling between its peers, repositioning himself in the world as well as each individual importance on the circle and in life. Therefore, the dance therapy is an invitation, which when embraced and accepted, provides one with the experience to bond to another human being and the world, reckoning the individual as a person and as an emotional being, favoring the recognition of the very personal issues on another peer, increasing emotional availability, which catalyzes a transformation from within, obviously depending on the degree of immersion on the experience [20,26,27] which is completely optional for the patient to take part.

Such program is not limited by offering only dance as integrative and complementary practices to ostomized people, but also several other activities to a much wider set of patients, which includes Tai Chi Chuan, Phytotherapy, Acupucture, Reiki Techniques among others. Although being held in high regard, the program has its deficiencies, such as not taking into consideration the transportation costs for the patient living in rural areas. Most of the Health centres offering complementary and integrative practices are widespread throughout the country due to the decentralized nature of Brazilian Unified Health System, however, that is not enough to ensure access to every Brazilian Citizen to such programs.

Regarding this complex scenario, although public health policies are constantly being elaborated and implemented to attend to the health demands in general, such specific needs of minority groups cannot be ignored [28]. The Health care process, as well as its public policies, must be aligned with the interests to secure the respect and recognition of people as unique individuals, aiming to recover the human dignity, attending to the Bioethical predispositions [29].

After all, the permanent training of health professionals regarding the impacts of as intestinal ostomy on QoL has great contribution on the care of the ostomized person, having a decisive importance on improving the Physical, Psychological, Social and Spiritual domains. Thus, National Public Programs approaching such issues - in regard to Complementary and Integrative Practices as public policies, is held in high regard for the intestinal ostomized person, being able to drastically enhancing people's QoL.

\section{References}

1. The WHOQOL Group. The World Health Organization. Quality of life assessment (WHOQOL): Position paper from the World Health Organization. Social Science and Medicine 1995; 41: 1403-1409. 
2. Kimura CA, Kamada I, Guilhem DB, et al. Quality of life in stomized oncological patients: An approach of integrality from Brazilian Unified Health System. J coloproctol 2016; 36: 34-39.

3. Kimura CA, Kamada I, Guilhem DB, et al. Quality of life of colorectal cancer patients with intestinal stomas. Journal of Carcinogenesis \& Mutagenesis 2014; 12: 1-7.

4. Kimura CA. Quality of life of cancer ostomy patients. 149 f. Dissertation (Masters in Nursing) - University of Brasilia. 2013.

5. Mahjoubi B, Mirzaei R, Azizi R, et al. A cross-sectional survey of quality of life in colostomates: A report from Iran. Health Qual Life Outcomes 2012; 10:1-6.

6. Kimura CA, Kamada I, Guilhem DB, et al. Perception of sexual activities and the care process in ostomized women. Journal of Coloproctology. Rio de Janeiro 2013; 33: 145150.

7. Fortes RC, Monteiro TMTC, Kimura CA. Quality of life from oncological patients with definitive and temporary colostomy. J Coloproctol Rio Janeiro 2012; 32: 253-259.

8. Burch J. Providing information and advice on diet to stoma patients. Br J Community Nurs 2012; 16: 479-84.

9. Torres CRD, Andrade EMLR, Ribeiro FMSS, et al. Quality of life of stomized people: An integrative review. Rev Enferm UFPI 2015; 4: 117-22.

10. Bonill-de-las-Nieves C, Celdrán-Mañas M, HuesoMontoro $\mathrm{C}$, et al. Living with digestive stomata: Coping strategies of the new physical reality. Rev Latino-Am Enfermagem 2014; 22: 394-400.

11. Kimura CA, Kamada I, Guilhem DB, et al. Reflections for health professionals on the quality of life of cancer ostomy patients. Ciências Saúde 2009; 20: 333-340.

12. Brasil. Ministry of Health. National cancer institute estimate 2016: Cancer incidence in Brazil. Rio de Janeiro: INCA. 2015.

13. Jemal A, Bray F, Center MM, et al. Global center statistic. CA Cancer J Clin 2011; 61: 69-90.

14. Iqbal F, Kujan O, Bowley DM, et al. Quality of life after ostomy surgery in Muslim patients. J Wound Ostomy Continence Nurs 2016; 12: 1-7.

15. Lenza NFB. Socio cultural characteristics and intestinal ostomy clinics and family in a Program Ostomy. Rev Eletr Enf 2013; 15: 755-62.

16. Martins LM. Rehabilitation of individuals with intestinal ostomy. British Journal of Nursing 2015; 12: 24.
17. Salomé GM,Almeida SA.Association of socio demographic and clinical factors with the self-image and self-esteem of individuals with intestinal stoma. J coloproctol Rio de Janeiro 2014; 34: 159-166.

18. Dabirian A, Yaghmaei F, Rassouli M, et al. Quality of life in ostomy patients: A qualitative study. Patient Preference and Adherence 2011; 5: 1-5.

19. Kiepe MS, Stöckigt B, Keil T. Effects of dance therapy and ballroom dances on physical and mental illnesses: A systematic review. The Arts in Psychotherapy 2012; 39: 404-411.

20. Behrends A, Müller S, Dziobek I. Moving in and out of synchrony: A concept for a new intervention fostering empathy through interactional movement and dance. The Arts in Psychotherapy 2012; 39: 107-116.

21. Souza MF. Dance contributions to the quality of life elderly women. Revista Digital 2010; 15: 1-12.

22. Aktas G, Ogce F. Dance as a therapy for cancer prevention. Asian Pacific Journal of Cancer Prevention 2005; 6: 408411.

23. Janyacharoen T, Laophosri M, Kanpittaya J, et al. Physical performance in recently aged adults after 6 weeks traditional Thai dance: A randomized controlled trial. Clin Interv Aging 2013; 8: 855-959.

24. Wosien B. Dance a way for all/Bernhard Wosien; edition Maria- Gabriele Wosien; translation Maria Leonor Rodenbach, Raphael de Haro junior. São Paulo: TRIOM, 2000.

25. Baptista AS. Effectiveness of dance in patients with fibromyalgia: A randomised, single-blind, controlled study. Clinical and Experimental Rheumatology 2012; 30:18-23.

26. Wosien MG. Sacred dance: Gods, myths and cycles, Sao Paulo. Triom 2002.

27. Frison FS. Circular dance and quality of life in women with mastectomies: A pilot study. $82 \mathrm{f}$. Thesis (MA)-State University of Campinas School of Medical SciencesUNICAMP. 2011.

28. Bernardes LCB, Araújo TCCF. Disabilities, bioethics and public policy: Perceptions of public officials and rights advisers. Ciênc Saúde Coletiva 2012; 17: 2435-2445.

29. Silva O, Guilhem D, Bampi LNS. Thirty life-changing minutes: Rapid anti-HIV diagnostic testing for parturients and prenatal access. Nursing in Focus 2012; 3: 211-215.

\section{Correspondence to:}

Cristilene Akiko Kimura,

Professor,

SQNW Quadra,

311 Edifício Montparnasse,

Bloco B Apto, 116 Setor Noroeste,

Distrito Federal,

Brazil.

Tel: 55(61) 81395839

E-mail: cris.akiko7@gmail.com 